\title{
A Review on Hyperloop Transportation System
}

\author{
Mohit Bansal1, Pravin kumar² \\ 1B.Tech Student, ${ }^{2}$ Assistant Professor \\ 1,2Department of Electrical Engineering, \\ 1,2Poornima College of Engineering, Jaipur, Rajasthan, India
}

\begin{abstract}
How to cite this paper: Mohit Bansal | Pravin kumar "A Review on Hyperloop Transportation System" Published in International Journal of Trend in Scientific Research and Development (ijtsrd), ISSN: 24566470, Volume-3 | Issue-3, April 2019, pp.447-451, URL: http://www.ijtsrd.co $\mathrm{m} /$ papers/ijtsrd228 31.pdf

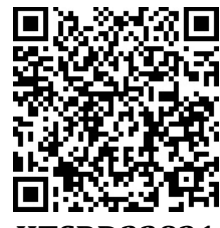

Copyright (C) 2019 by author(s) and International Journal of Trend in Scientific Research and Development Journal. This is an Open Access article distributed under the terms of the Creative Commons

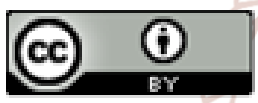
Attribution License (CC BY 4.0) (http://creativecommons.org/licenses/ by/4.0)

\section{INTRODUCTION:}

This transportation system was firstly proposed by Elon Musk, in this report he explained this project of ultra-high speed transportation system. This transportation system was planned for California (USA) to transport passengers between San Francisco and Los Angeles. This system uses a capsule which travels inside the tube at the speed of 1220 $\mathrm{kmph}$, which will cover the distance of $561 \mathrm{~km}$ in approx. 30 minutes.

This ultra-high speed transportation system called as Hyperloop system was so famous that many countries started construction for the use of this transportation system.

\section{CAPSULE}

Capsule is the part in which will travel inside the tube. So two types of Hyperloop capsules are:

$>$ Hyperloop passenger capsule

Supposing an avg. departure time of two minutes between capsules, a minimum number of 28

Passengers per capsule are required to meet 840 passengers per hour. By decreasing the time between the departures we can increase the Hyperloop capacity. During rush hours 40 capsules are required during movement at current model in which six are used for the loading and unloading purpose.

$>$ Hyperloop passenger plus vehicle capsule
ABSTRACT

system works on the principle of electromagnetic attraction forces. This ultrahigh speed transportation system in a vacuum medium with reduced problem for the passengers so we are solving this problem with the help of

Keywords: Hyperloop transportation system, ultrahigh speed vacuum train, synchronous motor, levitation, propulsion, electromagnet, permanent magnets, depressurization 


\section{TUBE}

The capsule used for travelling moves inside the tube and low air pressure inside the tube is maintained which increases the speed of transportation. 100 pascal pressure is maintained inside the tube which is $1 / 1000$ times pressure on earth. The drag forces on the capsule gets reduced because of the low air pressure inside the tube.

The tubes are constructed on the pillars which will ease the transportation system as it will not affect the traffic on the roads and will increase the area of construction. This tube also helps in the smooth journey to the passengers as it is inside the tube with the help of air bearings and suspension.

To control the speed and by accelerating and decelerating motors are used which will also guide the capsule in a respective direction.

\section{PROPULSION}

The need of the propulsion system are as follows-

$>$ In urban areas the speed should be low so it is maintained between 0 to $480 \mathrm{kmph}$.

$>$ For mountain or hilly areas the speed is maintained near $480 \mathrm{kmph}$.

$>$ For the long coasting area the speed is accelerated from 480 to $1220 \mathrm{kmph}$.

$>$ After the completion of coastal area the speed is decelerated again to $480 \mathrm{kmph}$.

The average power consumption is $28000 \mathrm{hp}$ or $21 \mathrm{MW}$ which involves the power desired by the propulsion motor including changes, air resistance interruptions, the train compressor (charging batteries) and to keep the vacuum in the tube throughout. So to fulfil the needs of the power in Hyperloop system we will cover it with solar plant as this system is very large.

We will connect batteries at the times of peak demand or peak power as the average power is $1 / 3$ times the peak power demand so batteries will fulfil the power demand but when the power demand is very high and the solar plant cannot withstand it only then the power from the grids will be given.

Large accelerators are used to increase the speed from 480 to $1220 \mathrm{kmph}$ at $1 \mathrm{G}$ in long coastal areas, small accelerators are used in urban areas and this system can also be used in mountain areas.

Induction motors are used to increase or decrease the speed of the capsule. We use induction motor rather than permanent magnet motor because of the following benefits:

$>$ The material cost is low as we are using aluminium in rotor.

$>$ The weight of the capsule is less.

$>$ The dimensions of the capsule are reduced.

In this we don't need to align the rotor to the air gap because of the lateral forces exerted by stator on the rotor.

\section{ROUTE}

Local topographical requirements, including the area of urban regions, mountain ranges, supplies, national parks, streets, railways, airplane terminals, and so forth. The course should regard standing structures.
For streamlined effectiveness, the speed of a case in the Hyperloop is regularly:

$>300 \mathrm{mph}(480 \mathrm{kph})$ where nearby topography requires a cylinder twist radii $<1.0$ mile $(1.6 \mathrm{~km})$

$>760 \mathrm{mph}(1,220 \mathrm{kph})$ where neighbourhood geology allows a cylinder twist $>3.0$ miles $(4.8 \mathrm{~km})$ or where nearby topography allows a straight cylinder.

These twist radii have been considered with the goal that the traveller does not encounter inertial increasing speeds that surpass $0.5 \mathrm{~g}$. This is trusted the most extreme inertial increasing speed that can be easily supported by people for brief periods. To additionally diminish the inertial speeding up experienced by travellers, the case as well as cylinder will join a system that will permit a level of 'banking'.

\section{VI. features of hyperloop technology}

Trains was presented by the popular American designer, creator, and specialist tycoon Elon Musk. In his work [1], he portrayed alleged "an alpha adaptation" of the Hyperloop transportation framework improvement in California (USA) interfacing two huge American urban communities Los Angeles and San Francisco. The length of the line is $561 \mathrm{~km}$ in separation.

This twin-tube street is proposed for transportation of travellers. It utilizes two cylinders. In one cylinder driving of the cases guarantees forward, through another cylinder in the invert heading. The cylinder width is $2.23 \mathrm{~m}$. The traveller case has measurements: $1.35 \mathrm{~m}$ in width, $1.1 \mathrm{~m}$ in tallness and 25 to $30 \mathrm{~m}$ long. The travellers in the case be situated in individual seats as in a vehicle. The container has a compartment for the hand rigging of travellers. The tablet suits two columns of seats with 14 situates in individual line, i.e., 28 travellers. The street will probably give the traveller traffic in the total of 840 individuals/hour, which permits accomplishing estimations of the measure of the drive at 7.4 million individuals/year. The development of the train is done utilizing direct electric engines. The moving engine component (rotor) is situated on the case while the cylinder joins the stationary engine stator which controls the vehicle. The motor uses an aluminium sheet as a rotor. The stator windings produce a directly moving attractive field performing on conductors in the field. The aluminium sheet, which is situated around there has swirl flows instigated in it, in this way producing a restricting attractive field. The two inverse fields repulse one another, produce movement of the case. It is conceivable to comprehend increasing speed of the case and its log jam. In the event of speeding up, it can achieve a high subsonic speed and give an intermittent reboot around each $110 \mathrm{~km}$. The base separation (in time) among moving contiguous cases ought to be no less than 30 seconds.

In the development of the case, it is important to affirm a base measure of erosion between the moving container and the cylinder. For this, we utilize the "air pad" mode around the case. In the front piece of the container, there is a blower, the delta of which takes a counter stream of air. The blower builds the approaching gaseous tension by multiple times and feeds it in clear extents through an arrangement of outlets to various pieces of the case surface. Accordingly, the tablet must go in the cylinder encompassed via air flows and ought not to contact the cylinder dividers. 
At the point when a strong body goes noticeable all around, an air pad before the moving body evades development. The quality of protection from development ascends with expanding velocity of the body. For lessening of air obstruction, it is proposed to keep a weight of $100 \mathrm{Dad}$ $(1 / 1000$ air weight) in the cylinder. The vacuum siphon framework keeps up the diminished required weight.

The vitality devoured in this by utilizing the air pad is 21 MW. Sunlight based batteries put on the external surface of the cylinders create this power. The cells produce $57 \mathrm{MW}$, i.e., totally spread the expended of vitality

The case conveys most extreme speed just on a straight way of the street, any sort of deviations from straightness lead to rate misfortunes. Subsequently, the principle line of the Hyperloop is set for the most part along a rectilinear parkway running from north to south. Because of the bended idea of the course in urban zones of Los Angeles and San Francisco, the container diminishes the speed on these segments of the street.

In open regions, arches fix both of the cylinders $5 \mathrm{~m}$ high, the separation estimated between them is $30 \mathrm{~m}$.

\section{CHALLENGES}

As indicated by [1], Hyperloop frameworks were proposed for the fast transportation of travellers. A strong body (for our situation, a case with travellers), moving noticeable all around at fast, delivers an air pad before it, which has a lot of protection from development. The opposition drive increments as for speed. To decrease the estimation of air opposition, Elon Musk proposed to maintain a weight of 100 Pascal's in the Hyperloop tube. The weight unit Pascal is meant in Dad.

One air weight contains 101325 Dad. Hence, the weight of 100 Dad weight is around $1 / 1000$ of the environmental weight adrift dimension. The vacuum siphons framework keeps up the fundamental decreased weight. Such sort of low weight exists in nature at an elevation of $45.7 \mathrm{~km}(150000$ $\mathrm{ft}$.) over the ground. Individuals can't live in an environment with such low air weight without the exceptional hardware (spacesuits).

Along these lines, guaranteeing the snugness of the traveller container is a noteworthy issue in the activity of Hyperloop traveller frameworks.

Being on the ground at the standard barometrical weight, during the time spent breathing, a man devours a specific measure of oxygen from the air. With expanding elevation and diminishing weight, the extent of oxygen in the climatic air diminishes, and the individual needs extra oxygen; else, he may pass on.

In case of a crisis including a depressurization of a traveller container, Musk proposes to utilize the cooling framework utilized on expansive traveller flying machine, see [1]. In case of a mishap, this framework radiates to every traveller through its place a defensive msk through which oxygen enters. Such frameworks are introduced and work on airplane that don't transcend the elevation $12000 \mathrm{~m}$. This height, as officially noted, is the point of confinement for the flights of subsonic traveller aircrafts. The pneumatic stress at this height is $145.5 \mathrm{~mm} \mathrm{Hg}$. or on the other hand $19399 \mathrm{Dad}$, which is a lot higher than the weight in a container of 100 Dad. In this way, hostile to depressurization frameworks for planes work at a higher outer weight than the low and increasingly hazardous weight made in the Hyperloop rounded framework. In the event that there is a quick depressurization of the traveller container in the Hyperloop tube, the flying machine cooling framework won't help.

The last strategy, which we are examining here, is related with a detectable increment in weight in the Hyperloop tube. The system utilizes a passage adaptation of vacuum lines with an inside weight of 100 milli bars (indicated as mbar). Note that 100 mbar $=0.1$ bar $\mid 104$ Dad. Subsequently, the weight in this framework is multiple times more noteworthy than in the Hyperloop framework (100 Dad). Accordingly, the air opposition in the development of the traveller capsule and vitality utilization expanded in this framework. Be that as it may, in the meantime, the plan speed remained rather high $-500 \mathrm{~km} / \mathrm{h}$.

This demonstrates it is conceivable to altogether expand the weight in the cylinder and in the meantime to acquire satisfactory specialized and monetary framework qualities.

For the Hyperloop traveller framework, we can build the weight in the framework's cylinder to an estimation of 19 399 Dad (weight at an elevation of $12000 \mathrm{~m}$ ). This will empower us to viably utilize the standard air ship frameworks to spare individuals amid depressurization.

Obviously, for this situation the specialized and monetary pointers of the vehicle framework are falling, yet the dimension of security for traveller's increments.

\section{SAFETY AND DEPENDABILITY}

The plan of Hyperloop has been considered from the begin in view of security. In contrast to different methods of transport, Hyperloop is a solitary framework that fuses the vehicle, impetus framework, vitality the executives, timing, and course. Cases travel in a cautiously controlled and kept up cylinder condition making the framework is insusceptible to wind, ice, haze, and downpour. The impetus framework is coordinated into the cylinder and can just quicken the container to speeds that are protected in each segment. With human control mistake and capricious climate expelled from the framework, not many wellbeing concerns remain.

A portion of the wellbeing situations beneath are novel to the proposed framework, however all should be viewed as with respect to different types of transportation. Much of the time Hyperloop is characteristically more secure than planes, prepares, or vehicles.

\section{$>$ On board traveller Crisis}

All containers would have direct radio contact with station administrators if there should be an occurrence of crises, enabling travellers to report any episode, to demand help and to get help. What's more, all cases would be fitted with emergency treatment hardware.

The Hyperloop enables individuals to venture out from San Francisco to LA in 30 minutes. In this manner if there should be an occurrence of crisis, all things considered, the best strategy would be for the case to impart the circumstance to the station administrator and for the container to complete the voyage in no time flat where crisis administrations would hold up help. 
Common occasions between a crisis and access to a doctor ought to be shorter than if an occurrence occurred amid plane departure. On account of the plane, the course would should be balanced, different planes rerouted, runways cleared, plane landed, taxi to an entryway, and entryways opened. A crisis in a Hyperloop case just requires the framework to finish the arranged voyage and meet crisis staff at the goal.

\section{$>$ Power Blackout}

Most by far of the Hyperloop travel remove is spent drifting thus the case does not require persistent capacity to travel. The case life emotionally supportive networks will be fuelled by at least two repetitive lithium particle battery packs making it unaffected by a power blackout. In case of a power blackout happening after a case had been propelled, every direct quickening agent would be furnished with enough vitality stockpiling to bring all cases at present in the Hyperloop tube securely to a stop at their goal. Moreover, straight quickening agents utilizing a similar stockpiling would total the increasing speed of all containers as of now in the cylinder. For extra repetition, all Hyperloop containers would be fitted with a mechanical stopping mechanism to convey cases securely to a stop.

In synopsis, all adventures would be finished of course from the traveller's viewpoint. Ordinary travel calendars would be continued after power was re-established.

\section{$>$ Capsule Depressurization}

Hyperloop containers will be intended to the most noteworthy security benchmarks and made with broad quality checks to guarantee their trustworthiness. In case of a minor release, the installed ecological control framework would keep up container weight utilizing the save air conveyed locally available for the brief timeframe it will take to achieve the goal. On account of a progressively noteworthy depressurization, breathing devices would be conveyed as in planes. When the case achieved the goal securely it would be expelled from administration. Wellbeing of the locally available air supply in Hyperloop would be fundamentally the same as air ship, and can exploit many years of advancement in comparable frameworks.

In the far-fetched case of an expansive scale case depressurization, different containers in the cylinder would naturally start crisis braking while the Hyperloop cylinder would experience fast re-pressurization along its whole length.

\section{$>$ Capsule Stuck in Cylinder}

A case getting to be stranded in the Hyperloop tube is exceptionally impossible as the case drifts most of the separation at fast thus there is no impetus required for over $90 \%$ of the voyage.

In the event that a container were some way or another to end up stranded, cases ahead would proceed their adventures to the goal unaffected. Containers behind the stranded one would be naturally educated to send their crisis mechanical slowing mechanisms. When all containers behind the stranded case had been securely conveyed to rest, cases would drive themselves to wellbeing utilizing little installed electric engines to control sent wheels.

All cases would be furnished with a hold air supply sufficiently incredible to guarantee the wellbeing of all travellers for a most dire outcome imaginable occasion.

\section{$>$ Structural Trustworthiness of the Cylinder in Danger}

A minor depressurization of the cylinder is probably not going to influence Hyperloop containers or travellers and would almost certainly be overwhelmed by expanded vacuum siphon control. Any minor cylinder holes could then be fixed amid standard support.

In case of a huge scale spill, weight sensors situated along the cylinder would consequently speak with all cases to convey their crisis mechanical slowing mechanisms.

\section{$>$ Earthquakes}

California is no more interesting to tremors and transport frameworks are altogether worked in light of quakes. Hyperloop would be the same with the whole cylinder length worked with the fundamental adaptability to withstand the quake movements while keeping up the Hyperloop tube arrangement.

Almost certainly, in case of a serious seismic tremor, Hyperloop cases would be remotely instructed to activate their mechanical crisis slowing mechanisms.

\section{Human Related Occurrences}

Hyperloop would highlight a similar abnormal state of security utilized at air terminals. Be that as it may, the ordinary take off of Hyperloop cases would result in a steadier and quicker stream of travellers through security screening contrasted with airplane terminals. Cylinders situated on arches would confine access to the basic components of the framework. Numerous repetitive power sources and vacuum siphons would restrict the effect of any single component.

\section{Reliability}

The Hyperloop framework containing all foundation, mechanical, electrical, and programming parts will be planned with the goal that it is dependable, solid, and blame tolerant over its administration life (100 years), while keeping up wellbeing levels that coordinate or surpass the security standard of business air transportation.

\section{DISADVANTAGES}

$>$ High speed of container (nearly at speed of sound) may make discombobulation the travellers venturing out because of vibration and jarring.

$>$ Initial cost of venture to have the framework set up is high. The long vacuum chamber producing requires progressively specialized abilities. Besides this is exorbitant and furthermore hazardous to keep up.

$>$ Land use rights will be worry for organization of the undertaking.

$>$ It has extremely high hazard to life when something incorrectly happens to the framework.

$>$ It has restricted space in the train and consequently individuals cannot move openly.

$>$ As Hyperloop utilizes steel for track, it extends and changes shape when outside temperature is changed. This may wreck the track of Hyperloop innovation. This should be considered while planning the framework dependent on condition of the area where it is being conveyed.

$>$ The establishment requires cutting of substantial number of trees. This prompts condition misfortune. 
$\mathbf{X}$.

The all out expense of the Hyperloop traveller transportation framework as sketched out is under $\$ 6$ billion USD (Table 1). The traveller in addition to vehicle variant of Hyperloop is including both traveller and load containers and the all-out expense is illustrated as $\$ 7.5$ billion USD (Table 2).

Table1. Complete expense of the Hyperloop traveller transportation framework.

\begin{tabular}{|c|c|}
\hline Segment & Cost (million USD) \\
\hline Container (40 cases) & 54 \\
\hline Container Structure and Entryways & 9.8 \\
\hline Inside and Seats & 10.2 \\
\hline Blower and Pipes & 11 \\
\hline Batteries and Gadgets & 6 \\
\hline Impetus & 5 \\
\hline Suspension and Air Orientation & 8 \\
\hline Segments Get together & 4 \\
\hline Cylinder & 5,410 \\
\hline Cylinder Development & 650 \\
\hline Arch Development & 2,550 \\
\hline Passage Development & 600 \\
\hline Drive & 140 \\
\hline Sun powered Boards and Batteries & 210 \\
\hline Station and Vacuum Siphons & 260 \\
\hline Licenses and Land & 1,000 \\
\hline Cost Edge & 536 \\
\hline All out & 6,000 \\
\hline
\end{tabular}

Table2. All out expense of the Hyperloop traveller in addition to vehicle transportation framework

\begin{tabular}{|c|c|}
\hline Segment & Cost (million USD) \\
\hline Load Container & $30.5(20$ cases $)$ \\
\hline Container Structure and Entryways & 5.5 \\
\hline Inside and Seats & 3.7 \\
\hline Blower and Pipes & 6 \\
\hline Batteries Engine and Gadgets & 4 \\
\hline Impetus & 3 \\
\hline Suspension and Air Course & 5.3 \\
\hline Segments Get together & 3 \\
\hline Traveller Just Case & 40.5 (30 cases) \\
\hline Case Structure and Entryways & 7.4 \\
\hline Inside and Seats & 7.6 \\
\hline Blower and Pipes & 8.2 \\
\hline Batteries Engine and Hardware & 4.5 \\
\hline Drive & 3.8 \\
\hline Suspension and Air Direction & 6 \\
\hline Parts Get together & 3 \\
\hline Cylinder & 7000 \\
\hline Cylinder Development & 1200 \\
\hline Arch Development & 3150 \\
\hline Passage Development & 700 \\
\hline Impetus & 200 \\
\hline Sunlight based Boards and Batteries & 490 \\
\hline Station and Vacuum Siphons & 260 \\
\hline Grants and Land & 1000 \\
\hline Cost Edge & 429 \\
\hline Absolute & 7500 \\
\hline
\end{tabular}

\section{FUTURE EXTENSION}

Hyperloop is viewed as an open source transportation idea. The creators energize all individuals from the network to add to the Hyperloop configuration process. Emphasis of the plan by different people and gatherings can help convey Hyperloop from a plan to a reality.

The creators perceive the requirement for extra work, including however not restricted to:

$>$ More development on the control component for Hyperloop containers, including frame of mind thruster or control minute gyros.

$>$ Detailed station structures with stacking and emptying of both traveller and traveller in addition to vehicle renditions of the Hyperloop cases.

$>$ Trades contrasting the expenses and advantages of Hyperloop with increasingly customary attractive levitation frameworks.

$>$ Sub-scale testing dependent on a further improved plan to exhibit the material science of Hyperloop.

\section{CONCLUSION}

A fast transportation framework known as Hyperloop has been created in this report. The work has nitty gritty two variants of the Hyperloop: a traveller just form and a traveller in addition to vehicle rendition. Hyperloop could transport individuals, vehicles, and cargo between Los Angeles and San Francisco in 35 minutes. Transporting 7.4 million individuals every way consistently and amortizing the expense of $\$ 6$ billion more than 20 years gives a ticket cost of $\$ 20$ for a single direction trip for the traveller variant of Hyperloop. The traveller just form of the Hyperloop is under $9 \%$ of the expense of the proposed traveller just fast rail framework between Los Angeles and San Francisco.

An extra traveller in addition to transport form of the Hyperloop has been made that is just 25\% higher in expense than the traveller just form. This variant would be fit for transporting travellers, vehicles, cargo, and so on. The traveller in addition to vehicle form of the Hyperloop is under $11 \%$ of the expense of the proposed traveller just rapid rail framework between Los Angeles and San Francisco. Extra innovative improvements and further advancement could almost certainly diminish this cost.

\section{REFERENCES}

[1] Hyperloop Alpha (pdf). SpaceX (12 August 2013). The first concept of the system proposed by Elon Musk on August 12, 2013.

[2] http://www.prnewswire.com/newsreleases/hyperloop-one-announces- semifinalists-ofits-global-Challenge-300387186.html

[3] The possible application of Hyperloop technology in the Handgun Zarubino. Materials of the Eastern Economic Forum (WEF-2016), September 2016,

[4] https://www.ontlease,ru/catalog/suhogruznye_morski e_kontejnery/

[5] Maglev, https://ru.wikipedia.org/wiki/maglev.

[6] https://www.boringcompany.com

[7] Dudnikov E., Advantages of a new Hyperloop transport technology / Proceedings of the 10th International Conference "Management of MaterialsofLarge6FDOH6\VWHP'HYHORSPHQW0/6'E, 2017.

[8] Ashcroft F. On the verge of a possible. - M;Alpina nonfiction. 2018

[9] Hyperloop One: images of the first Hyperloop full-scale test track released. Electrek.co. March 7, 2017

[10] https://en.wikipedia.org/wiki/Swissmetro 